\title{
Transforming the national body: choreopolitics and disability in contemporary Cambodian dance
}

\begin{abstract}
This paper analyses how dance traces geographies of nation and national identity. Focusing on contemporary dance in Cambodia, particularly in relation to disability, it examines how some dancers are shifting the constitution of the national 'body'. The paper extends geographical exchanges with dance studies by drawing upon the concept of choreopolitics and analysing how it produces variegated enactments of nationality. In the process, the paper works across different approaches to the study of nations and extends our understanding of how the nation is a performed entity.
\end{abstract}

Keywords: Cambodia, contemporary dance, disability, Epic Arts, geographies of performance, nationality

\section{Introduction}

This paper analyses how dance can reimagine the constitution and contours of the nation. Focusing on contemporary dance in Cambodia, it uses the concept of choreopolitics to investigate variegated enactments of nationality. Choreopolitics describes the relationship between kinetics and politics ${ }^{\mathrm{i}}$, but is concerned with the freedom to move and the ability to challenge existing bodily comportments through non-conformity. However, I suggest that choreopolitical expressions work across a dualism in geographical research whereby national identity is either located in material bodies or artefacts, or in affective domains that encompass, but exceed, these geographies. ${ }^{\text {ii }}$ As 
such, choreopolitics contributes to emerging research that connects different formations of national identity. ${ }^{\text {iii }}$

The relationship between the nation and the performing arts encompasses imaginations and practices that are multiply inhabited, involving degrees of consensus and contestation, inclusion and exclusion. The performing arts expose such tensions through their content, form, creative choices, emotional entanglements, and relationship to the state, enabling researchers to 'explore the paradoxes, ambiguities and complexities that surround nationality' ${ }^{\text {iv }}$. These negotiations are emphasised in post-conflict settings such as Cambodia where the legacies of the Khmer Rouge (1975-1979) over-determine the movement possibilities of the dancing body because $90 \%$ of artists were executed, or died from torture, starvation and exhaustion. The embodied repertoire of knowledge about robam boran (classical dance), which was nearly eradicated during this period, is seen as a national treasure that must be respected and preserved. However, Cambodia does not possess a national theatre building ${ }^{\mathrm{v}}$, government funding for the arts is minimal but improving, and the state responds to, and shapes, Cambodia's dance world. Dancers who have learned foreign dance styles through the international NGO arts sector, or who have used classical dance vocabularies in new ways, have historically been criticised for degrading the national art form. For instance, Sophiline Shapiro uses the classical dance lexicon to tell new stories, drawing upon existing gestural meanings and comportments but also adapting them to create her unique contemporary dance style, but her work was initially investigated by the government for not adhering to the strict rules of classical dance. ${ }^{\text {vi }}$ Dancers often use the word aphivordth (development, improvement) to describe the various modalities of contemporary dance in Cambodia ${ }^{\mathrm{vi}}$, lending legitimacy to these explorations by connecting dancers to an evolving tradition of praxis dating to ninth century Angkor. As Nelson ${ }^{\text {viii }}$ argues, in Cambodia, contemporaneity does not simply mean performance works being produced now, but encompasses an expansive understanding that connects performance to different times, spaces and dance traditions to produce multiple embodied aesthetics. What may look 'traditional' to a 
western eye can therefore be contemporary, as in the case of Sophiline Shapiro, and this exists alongside, and in dialogue with, a suite of Euro-American and Asian practices labelled 'contemporary dance' by the international art world. Innovation and experimentation are therefore not confined to any singular style. Dancers represent a seemingly timeless national culture but some are developing modalities of movement that produce new imaginations of the national 'body'. This article attends to some of these emergent configurations through a focus on disability, examining how this opens up which bodies can partake in national performances as well as their aesthetic qualities.

In what follows, I detail the concept of choreopolitics then review the existing literature on dance and nationality, particularly in relation to Cambodia and research on disability. After outlining my methodology, I examine how bodies that do not fit the embodied norms of classical dance, especially those that are disabled, carve a space within the national imaginary, and how dance can imagine new modes of collective belonging. I focus on three examples drawn from the work of the inclusive dance company Epic Arts, as well as that of able-bodied dancers who promote positive images of disability.

\section{Choreopolitics}

Taken from dance studies, choreopolitics 'rethink[s] the politics of movement' ${ }^{\text {,ix }}$ by challenging the Euro-American modernist association between dance and movement, particularly the ideal of a choreographically disciplined body. André Lepecki has explored how dancing bodies can resist an ontological relationship with 'being-in-flow' through practices of exhaustion, stillness, devotion and imagination, enacting a 'slower ontology'xi that reconceptualizes movement. ${ }^{\text {xii }}$ He argues that dance is characterised not by movement per se, but is a speech-act expressing mourning over the passing of movement and time. This links to his argument that dance is embedded in textuality owing to the association between dance and choreography. 
Choreographers and dancers who challenge the ontological association between dance and movement enact political resistance against capitalist modernity. Critics have highlighted the limits of labelling choreography in these oppositional terms by exploring how choreographic experimentation produces different political frames of experience whilst also initiating new possibilities over what dance can be. ${ }^{\text {xiii }}$ Here, I contribute to these discussions by discussing how different choreographic and embodied experiments related to disability produce a variegated political domain, including how they expose the limits of discourses about political transgression in the Cambodian context.

For Lepecki, the political is the freedom to move, requiring 'a choreographic imagination taking the dance, the choreographer and their audiences away from certain predetermined images of what a movement is supposed to look like, to sound like and to move like ${ }^{\text {siv }}$. Choreopolitics, as the interchange of choreography and politics, therefore opens out the enactment of movement and its spaces of sociability in ways that are emancipatory. Dancers expose and resist the Deleuzian 'society of control' ${ }^{\mathrm{xv}}$ whereby movement is disciplined as a general function of capitalism, but presented through the illusion of freedom: individuals can move their bodies however they wish, but as this freedom is tested, its limits become apparent. Capitalism demands that movements are prescribed, with power and choreography producing 'kinetic acquiescence ${ }^{\text {sxi }}$. In this, Lepecki links the society of control to what he terms, vis-à-vis Rancière's ${ }^{\text {vii }}$ concept of the police, choreopolicing. The dancing body is assigned particular places and modalities of movement, highlighting how power and control permeate social life so that individuals self-police their movements to conform. Choreopolitics works against this continuous control of the embodied 'distribution of the sensible ${ }^{\text {sviii }}$, offering the political as a transgressive domain of experimentation with, and through, movement that articulates 'the desire to live away from policed conformity'xix.

Such ideas resonate with non-representational accounts of dance in their understanding of how movement produces the future as a world of 'potential within which valued forms of life might be made and remade ${ }^{\mathrm{xx}}$. However, choreopolitics is not simply the kinetic freedom of 
expression, nor do its affective domains emerge from pre-conscious experience. ${ }^{\mathrm{xxi}}$ Rather, choreopolitics and choreopolicing exist in tension, with choreography conceptualised as a planned activity that produces alternative, affective modes of political being. Extant discussions of choreography in geography have risked being viewed as a domain of command ${ }^{\text {xii }}$ but choreopolitics views choreography as enabling the practice of freedom and non-conformity such that experimental and experiential worlds can emerge.

Here, I suggest that works grounded in disability are one way that practitioners are exploring bodily freedom, enacting choreopolitics by producing a more inclusive nationality. In Cambodia, dancing bodies are encultured to perform in ways that primordially represent the nation, but disabled bodies open out a more variegated terrain of movement, implicitly creating a more expansive national imaginary. In so doing, they also expose the limits of Lepecki's choreopolitics in the Cambodian context, those moments and spaces where 'the freedom to move' might be circumscribed. It is not only capitalism that choreopolices dance, but also the state and the Cambodian dance world. The three examples below therefore develop Lepecki's ideas to highlight how the choreopolitical is geographically patterned to produce degrees of non-conformity. Disabled and non-disabled dancing bodies create different choreopolitical configurations across different sites and scales of activity associated with nationality (for example, across a rural-urban divide, or from national to international disabled communities). In examining these formations, the paper contributes to an emerging body of research that illustrates how dancing bodies navigate, and produce, symbolic, everyday, and affective performances of the nation. ${ }^{\text {xiii }}$ Merriman and Jones ${ }^{\text {xxiv }}$ have outlined how research on nations and nationalism focuses on specific geographies in which the nation is embedded (bodies, artefacts, iconographies, landscapes) or on the affective and felt spaces through which nationality is enacted. Choreopolitics traverses these different understandings, with my reading of contemporary Cambodian dance illustrating how the constitution of the nation is fundamentally linked to bow bodies move. 


\section{Dance and Nationality}

Geographers have conceptualized dance as creatively producing 'embodied nationalism ${ }^{\text {’xv }}$, such as in Matless' ${ }^{\text {xxvi }}$ discussion of Morris dancing and rural English masculinity, or Narbed's examination of the 'recuperation and reinterpretation of collective imaginaries ${ }^{\text {'xvii }}$ through festivals in Ecuador. Similarly, Cresswell ${ }^{\mathrm{xxviii}}$, Aoyama ${ }^{\mathrm{xxix}}$ and Walsh ${ }^{\mathrm{xxx}}$ have examined the embodied tensions that arise when dances become associated with national values and identities, particularly when inserted into circuits of globalization. Although dances often symbolically represent the nation, their evolving geographical composition reflects how this relationship shifts. ${ }^{\text {xxi }}$ Dance therefore produces a 'contingent and temporary configuration of different bodies and objects [with] the potential to affect, to unify differently marked bodies 'xxxii that are linked to 'unsteady'xxxii forms of affective national belonging.

In dance studies, the nation is a 'central organizing principle $e^{\text {xxiv }}$ of dance, with tourism, international arts festivals, interest in heritage by states and NGOs (especially UNESCO), and cultural globalization all driving how dance creates and expresses national communities. ${ }^{\mathrm{xxv}}$ As in geography, dance is a modality of action that embodies and represents the nation whilst also evoking feelings that potentially undermine statist agendas. ${ }^{\text {xxvi }}$ As Hughes-Freeland argues, the dancing body is politically charged because it is a visible form of materiality that is 'energized and cognizant, generating meanings and sense. ${ }^{\text {xxxvii }}$ It also has metaphorical force whereby 'poetics

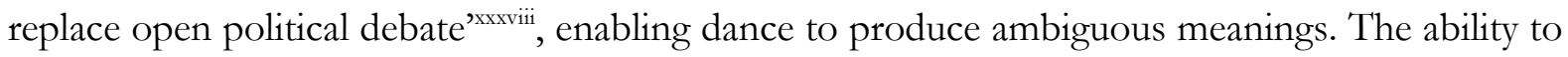
create meaning and experience, alongside this multivalent opaqueness, gives dance its power, and enables it to simultaneously reproduce and challenge nationality.

However, the focus on creative politics in non-Western or postcolonial contexts distinguishes research on nationality in dance studies from that in geography. Research in dance studies emphasizes the interplay between liberation and constraint, but also drills down into how the state influences performance cultures and how dancers respond to such interventions. 
Concerns focus on who can re-imagine and embody the nation, particularly when the nation-state and the performing arts are aligned to produce particular kinds of subjects. ${ }^{\text {xxix }}$ This work also explores how dancers are caught between agendas vis-à-vis their moving bodies. For instance, Plancke has examined the tensions underpinning how young people are reviving 'traditional' dances in Rwanda in ways that embody ideals of the new Rwanda. ${ }^{\mathrm{xl}}$ In Cambodia, Tuchman-Rosta investigates how the government's promotion of classical dance for economic boosterism complicates the enactment and preservation of this art form. ${ }^{\text {xli }}$

In Cambodia, dance and national identity are closely intertwined, with classical dance in particular being 'essential to the perpetuation of Cambodia as a cultural and political entity'slii. Conventionally, there are four dance forms: classical dance (robam boran); the all-male masked dance (lakhon khol); shadow theatre (sbek); and folk dance (robam propeiny). The first three tell stories from the Reamker, the Cambodian Ramayana, and thus have religious significance. They also contain different roles: female (neang), male (neay rong), giant (yak), and monkey (sva). From the mid 1800s to the 1960s, women performed all classical roles until Queen Sisowath Kossamak adapted classical dance for modern audiences (e.g. by shortening performances). Dancers train from childhood in a grounded mode of embodiment, with weight low and centred, a S-bend in the spine, knees bent, arms extended, elbows hyper-flexed, and hands, fingers and toes bent backwards. Movement occurs in a horizontal, rather than vertical plane (except for sva) and is based on figures of eight or circular patterns that reflect serpentine mythical characters. Classical dance comprises over 4,500 hand gestures that are combined with bodily postures (kbach), music and sung poems to create specific meanings, from emotions (joy, grief, love) to types of movement (flying). Dancers train according to socially encoded modes of physicality; hence petite, beautiful girls train in neang, and taller or stockier girls in neay rong. Dance masters told me that if Queen Sisowath Kossamak deemed a dancer 'ugly' she told them to train in yak as a mask would hide their imperfections. These embodied norms highlight how the presence of a disabled dancer, of a 
body that does not fit convention, immediately challenges the associations made with classical dance, and thus nationality.

Classical dance is historically bound to elite social and political power, with dancers performing for the king and operating as intermediaries with the gods. When Cambodia became a French Protectorate in 1863, dancers began performing for foreign dignitaries and for the public on the monarch's birthday, connecting dance to the state-led promotion of national identity. This was cemented in the 1940s under King Norodom Sihanouk when classical dancers accompanied him on diplomatic tours overseas. Some of Cambodia's most recognisable dances were choreographed for these visits, such as the Apsara, which has become an iconic symbol of Cambodian nationality. ${ }^{\text {xlii }}$ The beautiful dancer in a white or beige sampot (bodice), two-tiered crown, and frangipani flowers in her hair is one of Cambodia's most recognisable images. Legends of the Apsara associate them with the birth of the country, and Apsara carvings decorate temples at Angkor, the symbol of Cambodia, with this connection cementing the dance's seemingly primordial association with nationality. However, under the Khmer Rouge (1975-1979) dancers were explicitly executed owing to their associations with elite society. After the Vietnamese ousted the Khmer Rouge in 1979, dancers gathered to reconstruct the repertoire. As Shapiro-Phim notes, dancers accepted the 'nationalist master narrative' ${ }^{\text {,liv }}$, with the Ministry of Culture and Fine Arts (MCFA) sending artists to contested areas of the country to perform, harnessing dance's symbolic power to re-claim and re-establish the nation. ${ }^{\text {xlv }}$ Classical dance provided 'the ideal model of Khmer character and morals ${ }^{\text {xlvi }}$ as based on elite court culture, representing grace, beauty, refinement, discipline, respect, love of the country, and balance - both of the dancing body and its morality, but also of the social body of the nation.

Little research examines current incarnations of dance in Cambodia, and even less focuses on bodies that do not fit normative expectations. ${ }^{\text {xlvii }}$ Some Cambodian dancers are linked to the state, working at the Secondary School of Fine Arts (SSFA) and the Royal University of Fine Arts (RUFA) as teachers, or at the MCFA's Department of Performing Arts (where dancers perform 
on state visits). Many dancers also find employment in the tourist and corporate economies, and work with arts NGOs which are a key space for exploring new modalities of movement. .viii $^{\text {. }}$ Dancers therefore traverse sites with differing degrees of choreopolitical potential to open up a varied political terrain: the classical repertoire as conventionally performed in state settings; new dances or adaptations created using the classical lexicon; and works created using dance styles from Europe, America and Asia that may, or may not, be melded with classical movements. Dancers describe how the idea for a dance makes it contemporary, being drawn from everyday experiences and expressed through choreography that draws upon different vocabularies. Although classical dance is not a static form, with even the Royal Ballet creating new works and reconstructions, contestations over 'contemporary dance' in Cambodia are greatest when considering interchanges with styles from outside Cambodia. The resulting debates over artistic practice reveal concerns over cultural loss and degradation. As dance is historically embedded in the reproduction of the Cambodian nation, concerns over expression are partly also concerns over the constitution of the national body.

\section{Dance and Disability in Cambodia}

These concerns are illustrated when considering performances by disabled bodies. Research on disability and dance is framed by narratives of inclusion, placing the disabled body as a transgressive outsider: 'When a disabled dancer takes the stage, he or she stakes a claim to a radical space, an unruly location where disparate assumptions about representation, subjectivity and visual pleasure collide. ${ }^{\text {xlix }}$ Narratives about discrimination impeding the expressive potential of the disabled body, and the potential for disabled dancers to challenge stereotypes, are important. ${ }^{1}$ However, Cooper-Albright ${ }^{\text {li }}$ criticises the idea that inclusion reduces inequalities. Framing disabled bodies as triumphantly able to overcome their differences by performing normative comportments reinforces hierarchies and fails to appreciate the aesthetic sensibilities of 
the dancing disabled body. However, there is a pleasure and empowerment in performing normative choreographies that is critically transformative. Disability can question existing 'ways of doing, ways of knowing ${ }^{\text {lii }}$ to provide new or positive body images. Indeed, research on disability and mobility has queried the ideals of the dancing body by emphasising collaborative and inclusive approaches that integrate different embodied abilities. liii

In Cambodia, disability is stigmatized, with discrimination and marginalization being rife, and narratives of 'pity' and 'inability' dominating ideas around what disabled people can

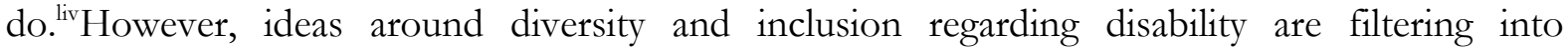
Cambodia's dance world. This paper traces some of the resulting experiments, illustrating the multiple configurations of contemporary dance and its choreopolitical potential. Some practices, such as in the work of Epic Arts, take an inclusive approach that entails dancers with different disabilities working together and with non-disabled dancers to experiment with movement forms. ${ }^{\text {lv }}$ Others, such as in Soy Chanborey's The Real (2015), entail able-bodied dancers developing choreographic vocabularies that reflect disabled experiences. It is worth noting that disabled dancers do not train at SSFA or RUFA, and to be called a professional dancer in Cambodia conventionally means one has graduated from these state institutions. There is, therefore, less conception of a professional disabled dancer, and, at first glance, disabled dancers exist outside state structures. However, Epic Arts have developed South East Asia's first inclusive dance company from their students. Epic Encounters is professional in international dance world terms, and their efforts, alongside those of dancers like Soy and other arts NGOs, are shifting the terrain for disabled dancers in Cambodia. At the MCFA's first Contemporary Dance Festival in 2018, both Epic and Soy presented work, signalling an increased acceptance of disability. However, this is a long-term, stuttering process that is complicated geographically by local responses (see below). It is also occurring under the banner of contemporary dance which is an emerging form, even as it includes the classical vocabulary, thus choreopolitical possibilities are fluid and may be thwarted. 
Nevertheless, I argue that these works derive choreopolitical potential from how they shift the extant corporealities, movement patterns, and aesthetics of the national art form, which is often practised quite strictly in state settings despite its evolution. They both challenge and reproduce 'kinetic acquiescence, ${ }^{\text {svi }}$, but they also articulate an affective freedom from choreographic enactment that is aligned with choreopolitics. As the link between dance and nationality in Cambodia is deeply ingrained, I suggest that this work loosens the parameters of the national body. Dancers may not view their work so directly in these terms, and given Cambodia's current political climate, do not always state their intentions in case they are perceived as political opponents. However, non-disabled contemporary dancers do discuss the development of national culture through creating contemporary dance and are government employees. Sophiline Shapiro's experience mentioned above signals that the state views dance as a realm through which it is represented and in which it can intervene. An organisation like Epic Arts is also concerned with positively promoting disability in Cambodian social and cultural life. As such, it is possible to read contemporary dance works for their articulation of a national imaginary but dancers often discuss the abstraction in their work, allowing a variety of readings to emerge and sidestepping overt questions of intent in a politically charged context.

\section{Methodology}

Geographers use practice-based methodologies to explore dance and its embodied spaces, experimenting with movement, writing, diagrams and notation ${ }^{\text {lvii }}$. For instance, Veal's exploration of the choreographic notebook combines methodologies from dance studies and social science to 'attend to the inherent corporeality of dance practice ${ }^{\text {pviii }}$. The question of how to capture the performing body for analysis has long been debated in dance and performance studies. This is because the expressive potential of the body, and its contexts of production and reception, are often reduced when translated into written or visual forms. ${ }^{\text {lix }}$ 
Here, I produce dance ethnography as a type of Geertzian 'thick description" ${ }^{\text {gl }}$ that also responds to Davida's ${ }^{1 \mathrm{i} i}$ emphasis on the wider art world of dance. My approach is to analyse the personal and socio-political contexts in which works are created, attending to 'narrative, iconographic gestures, symbolic images, social relationships in choreography, but also [...] how meaning is literally embodied in the dancer's physicality, in the phenomenological realities of weight, space and movement intentionality ${ }^{\text {lxii }}$. I present sections of performance analysis for discussion given the choreographic focus of the paper and combine this with interview quotations from dancers and key NGO figures.

The paper is informed by ongoing research that includes over 35 semi-structured interviews and two focus groups with dancers, choreographers, and executive directors of arts NGOs, conducted in Khmer (in translation) and English/French with the author. These were transcribed and coded using NVivo to draw out key themes. Respondents are not always anonymous because this is not possible when discussing particular companies or productions. My analysis is therefore careful in outlining what imaginaries of the nation might be being constructed, particularly given Cambodia's repressive political climate. My research draws upon observations of rehearsals and performance analysis of case study productions, both live and recorded. Reviews are limited and are often descriptive because media is state-controlled, the arts are an emergent industry, and feedback is locked into student-teacher relationships. My research has predominantly focused on the dance scene in Phnom Penh, but here I discuss the work of Epic Arts in Kampot. My selection of case studies is driven by themes emerging across a body of work, that, in this instance, speaks to the choreopolitical re-working of nationality through disability.

It is also briefly worth reflecting on my cross-cultural experience. Given that Cambodian dancers train from childhood, I cannot claim an in-depth knowledge of these forms. However, this does not mean that understanding is not possible. I have learned key hand gestures, movements and stories from books, videos, and from partaking in classical and contemporary dance workshops in Cambodia. I did not seek these out of the desire to exotically consume a 
culturally different performance form (though unconsciously that may be a factor), but to gain understanding of classical, and, by extension, contemporary dance. I also wanted to be respectful as, like learning a language, learning about dance in Cambodia shows a desire to gain cultural understanding, particularly among dancers - even though there are inevitably gaps in my knowledge and new works sometimes draw on Euro-American styles that I am familiar with 'reading'. In a limited sense, I therefore have ‘corpo-realities ${ }^{\text {'xiii }}$; experiences held in the body that can be used alongside social science methodologies when writing.

\section{Nationality, Choreopolitics and Disability}

This section examines the different directions in which contemporary Cambodian dance moves vis-a-vis disability, and the variegated choreopolitical formations of nationality that result. As indicated, choreopolitics entails the 'redistribution and reinvention of bodies, affects and senses through which one may learn how to move politically, how to invent, activate, seek or experiment with a movement ${ }^{\text {Ixiv }}$ through choreographic reworkings that unsettle assumptions about how bodies should move, but this need not mean creating oppositional politics. Although the goal of choreopolitics is embodied freedom, in a Cambodian context experiments are modest because they encounter nationality. In the process, the dancing body can be made more inclusive, opening up who constitutes the nation and how nationality is expressed.

There are many groups and dances that rework the classical dancing body. However, experiments with/about disabled bodies have, perhaps, reached the furthest in connecting ideas around nationality with choreopolitical possibilities. The work of Epic Arts is a good example. Epic Arts teaches art forms to young disabled Cambodians in order to promote self expression and build confidence as part of a broader programme of advocating for disability rights. They use an inclusive approach that brings together different corporealities (disabled and non-disabled) in a way that respects and builds upon everyone's abilities so that individuals learn from one another. ${ }^{\text {lxv }}$ 
For instance, exercises and games can be undertaken by everyone, with choreography emerging from the resulting multiple physical expressions. This approach contrasts with 'disabled arts' which carries connotations of inequality and deviation from a supposedly 'normal' body. ${ }^{\text {lxi }}$ Epic Arts students also learn skills such as literacy, business management, teamwork and confidence alongside and through their arts activities. The NGO runs local enterprises, particularly a café, where students are given work placements, and hosts free performances in and around Kampot. Epic Encounters create works that address Cambodian issues or themes, but these also speak to an international contemporary dance circuit - within and beyond disabled framings. These professional dancers (who have different disabilities) can be seen playing football together in the city centre on an evening, highlighting their confidence in appearing in public, and their enactment of a choreopolitical expression that challenges conservative cultural assumptions that disabled people should be kept in the choreopoliced space of the home. Epic Arts thus attempts to change a dominant cultural perception of disabled people as incapable, as needing pity and care, and promotes positive images of disability locally, nationally and internationally.

First, I examine how the dancing disabled body creates different degrees of choreopolitical possibility in Epic Arts' practice. Epic Arts hires choreographers or dancers, usually from abroad, for 1-2 years to work on their programmes. They come from different backgrounds, including contemporary dance, contact improvisation, and community arts, but many have long-standing experience of using dance to support self-expression among marginal groups, including those with disabilities and educational differences. Often they want to help students grow in confidence through creative practice, but there is also a desire to promote equal opportunities. This chimes with Epic's inclusive approach, such that dance is not codified choreographically:

What we do is based on how you move and how you can make your body connect to each other. As people with disability it was really new and surprised that people like me could be part of the dance, part of the movement. Because Cambodian arts it has to be really physically perfect 
body to do the Apsara dance. So I surprised to take part in arts by whatever my body could do. Freely express yourself, so that means a lot to me. Like I was touched by freedom of your eyes, freedom of your skin, you can use different ways of doing things. That was really empowering $[\ldots]$ there's no pressure, go and explore and [...] wow, yes, I can do so many things. ${ }^{\text {, lxvii }}$

'Cambodian dance is very restrictive [...] you have to put your hand in this particular position. Well if you haven't got a hand there, then you can't do that. [...] It automatically means you can't be included. lxviii $^{\text {le }}$

These quotations highlight the choreopoliced and exclusionary embodied norms of classical dance as the material representation and enactment of nationality. However, Epic's approach reorients the body choreopolitically vis-à-vis freedom and non-conformity as Lepecki suggests. Perfection does not come from choreographic mastery of dance, but from finding a way to express oneself beyond personal and societal expectations. This can be achieved through the skin, through touch, in bodily sites not automatically grounded in visual perception, moving away from the embodied ideals associated with classical dance. Epic Arts therefore 'construct(s) new images and ways of imaging the disabled body ${ }^{\text {gxix }}$ by valuing the movement possibilities of different bodies and their potential to create new aesthetic forms. These experiments are harnessed to create educational and interactive performances that address social issues, such as driving motorbikes (a leading cause of accidents and death). Epic's practice thus moves away from the elite formal reproduction of nationality and towards its everyday expression through addressing concerns or experiences in Cambodian society. This dovetails with a wider impulse in contemporary Cambodian dance 'to address some of the problems or questions that Cambodians have today [...] to inform, to make people think, to sometimes criticize or simply to be the expression of an artist ${ }^{1 \mathrm{lxx}}$. 
However, dancers in Epic Encounters have experimented with classical dance in making new works, exposing the limits of an approach that opens up choreopolitical potentials through the freedom to move:

'They are interested, 'Oh can I use that? Can I make something new from that?' So their idea is not just want to do it because it is traditional Cambodian form, they want to test out how their body works, they want to push themselves and do things in their own way. , $^{\text {lxi }}$

The impulse behind these experiments was not to directly experience or challenge the proscribed physicality of nationality, nor to normalize disabled dancing bodies (though indirectly these are factors) but to explore affective capabilities and find new movement routes. However, the state can choreopolice the performing disabled body at a provincial level, particularly in a rural locality like Kampot where artistic practice often remains traditional. When Epic Arts created Hip Hop Monkey by bringing together sva and hip hop, the NGO had to visit the local MCFA branch as the dance was initially seen as disrespectful because it used contemporary movement and was performed by disabled dancers. Epic Arts obtained a permission letter from the Ministry to perform it after explaining that 'we have people with disabilities, so they can't do the movement in the "right way"'lxxii. This local choreopolicing of the nation reflects concerns that when disabled dancers reproduce extant choreography, negative comparisons are drawn that reinforce exclusion. It also highlights that the state has tried to fix the relationship between dance, nation and culture across different sites and scales of activity, rather than seeing these as interconnected, evolving domains. Experiments with the classical vocabulary that hold choreopolitical potential by altering the aesthetics of dance through the disabled body, are viewed as shifting the form and constitution of the national body, and so can be shut down or scrutinized. Whilst some contemporary Cambodian dancers (who are classically trained) have worked with Epic Arts as teachers, others refuse to do so because they are not comfortable with disabled dancers. The Cambodian dance 
world thus also contains degrees of choreopolicing that attempts to confine particular bodies to particular modalities of movement.

The second articulation of choreopolitics focuses on able-bodied professional dancers experimenting with movement vocabularies based on disability. At a contemporary dance showcase held by Amrita Performing Arts, Soy Chanborey choreographed The Real (2015), a piece based on his disabled father who has lost a leg (Figure 1). The dance is grounded in Soy's professional training in lakhon khol giant role but uses postures and gestures from this form alongside movements based on his father's daily routines. Using everyday life as inspiration for dance is well-established praxis in Europe and North America as, since the 1960s, postmodern dance has collapsed the aesthetic divide between dance and other forms of movement. These ideas filter into Cambodia as dancers work with choreographers from abroad. When creating a new work, Soy realised that, 'I see my father everyday. He works in Watthan [an artisan co-operative run by disabled people] and I think about exploring their difficulties and their movement. I always promote about disability, because a lot of people have disabilities, they want to show their capability, but they don't have change. . $^{\text {xxiii }}$ Soy initially wanted to work with different people in Watthan, but found that, 'Some don't want to show they are disabled to other people, and don't want to be in the camera, so I go back and work with my father. ${ }^{\text {,lxxiv }}$ Such comments highlight the cultural feelings of shame attached to disability and difficulties around discrimination, but the impetus for the dance came from the desire to create a space of visibility for disabled people.

$<$ Insert Figure 1 here $>$

In The Real (reflecting the 'real life' of Soy and his father) Soy references the movements of sewing machines and the repetitive smoothing and stacking actions of his father's work as a bookbinder, particularly his use of glue and knives. These refrains of movement are introduced to the audience during a voice over, where his father describes his upbringing as the son of two 
farmers, becoming a moto taxi driver, the incident that disabled him (he was shot when a thief stole his motorbike), and the difficulty of finding work owing to discrimination. During this monologue, Soy dances slowly in a low position, hardly standing, spatially compressing his classical movements or performing them crouching, sitting, or lying on the floor on his back or side. This contrasts with the tall, upright, expansive, often forward-facing posture of a giant role, and derived from Soy exploring how he could walk with one leg like his father. Crouching on the floor, he pulls the weight of his body forward using only his arms such that his movement appears as a weighted effort. He performs a confined space into being, one in which his body cannot reach or stretch out, expressing the restricted and difficult nature of movement for some disabled people.

Soy then sits to one side and we watch a short film of his father working, where the some of the choreography's origins become apparent. The film focuses on his father's 'daily choreography', on his hands, on their repetitive rubbing and measuring actions amidst the cloth, packing, cotton reels, irons and sewing machines of his trade. Importantly, his disability is not spectactularised, rather the emphasis is on a normalised movement vocabulary that happens to be linked to disability. Soy then starts dancing again, creating a movement conversation between the two men, with moments where the focus is on the movement in the film and his father, moments when Soy's expression simultaneously moves with and exaggerates or develops that on screen, and moments where Soy responds using lakhon khol to his father's life, such as when he sampeabs (places hands palm together to a bowed forehead) to his father as a mark of respect, or when he enacts a fight scene that, whilst following lakhon choreographic convention, expressively becomes more painful as he hears about his father's disability. The Real, therefore, does not side-step classical vocabularies, nor does it consider how disabled bodies might perform classical vocabularies. Rather, it brings lakhon khol movements into dialogue with those from everyday life to develop a movement lexicon grounded in disabled experiences.

As Veal ${ }^{\mathrm{lxx}}$ has illustrated, able-bodied dancers can expose how bodily comportments are normalised in exclusivist ways. Here, the choreopolitical patterning of the dance is varied, as it 
encompasses classical vocabularies alongside expressions that change the movement, appearance and capacities of those vocabularies. Classical choreography is the realm of choreopolitical experimentation, with the dance expanding existing choreographies and their national associations, blurring elite and everyday domains to open up whose lives can be represented through dance. When Soy developed the piece for the MCFA Contemporary Dance Festival he talked about making it less literal in order to evoke ideas and movements (such as walking when disabled), rather than expressing them directly. The soundtrack also changed from the sounds and rhythms of his father's workplace to the use of pin peat melodies that traditionally accompany classical dance and lakhon khol. These changes were made in response to feedback from audiences, his peers and contemporary dance teachers. In part, they signal a desire to be part of the international contemporary dance world via an aesthetic of 'abstractness' which, in turn, operates as a mode of choreopolicing. The changes also reflect the context of the festival and the choreopolicing of contemporary dance and self expression in Cambodia. The use of pin peat harmonies, for instance, could be read as rerouting choreopolitical expressions back towards the familiar, but they also ground the dance distinctly in Cambodian culture, even when the movement may be harder to locate geographically. There are, therefore, varied relationships between movement, choreopolitics and the nation that shift with time and context.

My final example, an Epic Arts YouTube parody video, analyses the affective dynamics of choreopolitics in relation to, but also beyond, nationality. In 2016, Epic Arts re-created Taylor Swift's Shake it Off video because lyrically it provided an inspiring message of how people with disabilities can overcome barriers and discrimination. ${ }^{\text {lxxi }}$ Previous Epic Arts parodies of Pharrell Williams' Happy and Mark Ronson and Bruno Mars' Uptown Funk similarly promote ability and visibility, substituting locations in the original videos with sites around the cityscape of Kampot. However, Shake it Off was filmed in the capital, Phnom Penh, moving from the local to the national, the rural to the urban, and brought together arts NGOs from across Cambodia as well as artists such as Tiny Toones. Together they perform the hip-hop, robot dancing, cheerleading, gymnastics, 
and contemporary dance of Swift's video. Epic's version also substitutes dance forms, for example, the Apsara and Peacock dances are used as Cambodian forms instead of western ballet. The video is inclusive, with differently abled bodies performing together throughout the dance sequences. As such, it also speaks to the diversity agenda of the funders: the European Union and UNESCO in partnership with the International Fund for Cultural Diversity, as part of a project to build diverse cultural industries in Cambodia.

The parody illustrates the variety of Cambodian arts and how they encompass different performances of the contemporary (including the 'traditional'), particularly as mediated by cultural globalisation. It also demonstrates how those with disabilities can perform multiple choreographies. However, there are subtle shifts. For instance, the difference that disability makes is celebrated through lingering close-ups, such as in the gymnastic wheelchair breakdancing and handstands, which illustrate the dancers' strength and flexibility. Elsewhere, disability seems to disappear and the performers are simply a group of dancers. As the lead singer, Onn Sokny, Epic Arts' Co-Director, playfully embodies each dance style, and her own disability from polio is foregrounded through the constant presence of her crutch. We see her laughing as a dance master bends her hands into shape, as she turns up in a monkey onesie that is at odds with classical monkey costumes, gets over-enthusiastic singing and playing instruments, and when her throwing of a scarf or pom pom goes awry. In part, the parody promotes an inclusive vision of an artistically revived Cambodian nation. Indeed, it opens with Onn wearing a krama, or Cambodian checked scarf, with the national flag sewn into it as she warms up alongside the other dancers. In closely reproducing the choreography of Swift's video, the parody seems to reaffirm the ideal bodily aesthetics associated with existing dance comportments. However, a choreopolitical perspective emphasises that choreography is enabling, and here, copying and adapting movements articulates a desire not to necessarily be the same in a way that is policed, but to be equal within the capabilities of individual bodies that inevitably produce difference. The fact that disabled bodies are doing classical Cambodian movements, especially the iconic Apsara, is radical (for some, offensive) and 
can be read as staking a claim for inclusion. The presence of Onn's crutch on the ground as she enacts Apsara gestures sitting, rather than standing, is subtle but powerful, and is a choreopolitical expression that transforms the dance vocabulary into what she can do, rather than what she cannot. In the final segment, the backdrop is pulled away and we see young disabled people with their families dancing in Phnom Penh's streets, at the National Museum, in tuk tuks and coconut stalls, on construction sites, alongside, and sometimes indistinguishable from, the city's residents. The video reconfigures how the national body looks and performs by working across sites of iconic (Apsara, National Museum) and everyday (tuk tuks, street vendors) nationalism. In so doing, all the bodies appear hip whilst challenging the invisibility of disabled bodies in particular.

Yet, from all of this, what really emerges is the fun and enjoyment among those taking part. Everyone 'gives their all' to the performance; they appear carefree, confident, unconcerned. As Swift's stand-in, Onn's onscreen presence sparkles as she challenges perceptions about what she is able to do, with the opening frame reading; 'I am a woman with a disability and people have always told me 'you can't' and 'you won't', but I never listened. No matter what the barrier, you can overcome anything, you just have to shake it off. ${ }^{\text {. Ixvii }}$ It is also hard not to feel uplifted after watching this video. Here, Epic Arts starts to move beyond a form of choreopolitics that reworks how, where, and to whose beat the national body moves. Instead, choreographed bodies individually marked by difference in terms of capability and capacity, produce a mode of expression that is collective and inclusive. This is reinforced by the sign language raps (a meaningful expansion of the finger movements in Swift's video) that roughly translate as 'individuals, people, globally newly equal.' The raps use signs shared across different sign languages, making them translatable across cultures and able to speak to an international deaf audience. Although raps are not translated onscreen for viewers, the video focuses on the hand movements in close-up, making sign language part of the wider dance vocabulary. Their meaning, alongside their positioning as performances, becomes part of the video's message of equality. The raps, like the parody as a whole, harness feelings of hope, pride and fun, to invite viewers to be 
part of a global community grounded in fairness. As such, this video is fundamentally choreopolitical because the re-patterning of the individual dancing body reaches out to offer a mode of collective existence no longer framed by nationality, but by new forms of infectious energy.

\section{Conclusion}

This paper has examined some of the experiments currently circulating in Cambodia's dance world and their relationship to the expression of nationality. By focusing on disability, it traced the emergence of choreopolitics from choreographic re-routings of the performing body and its affective dynamics. In undertaking these varied transformations of classical dance, contemporary Cambodian dancers inch away from the concerns, agendas and aesthetic preferences of a political and religious elite. The result can be read as the imagination and performative enactment of a national dancing body that is more inclusive, equal and responsive.

In conducting this analysis, the paper offers new perspectives for geographical research on the performing arts and on national identity. It has examined how the performing arts can reimagine the (geo)political formation of the nation, providing different insights into the role of the state in influencing the parameters of artistic production than current accounts of creativity. It moves beyond accounts of policy-making or economics to highlight the shifting, contradictory terrain that artists navigate. The paper achieves this by developing intersections between research in cultural and political geography, and that in performance and dance studies, interrogating how the dancing body is a contested space open to multiple choreographic formations. By using ideas of choreopolitics, the paper offers a nuanced way to conceptualise how choreography produces variation in the type and tenor of the dancing body's political formation. ${ }^{\text {lxviii }}$ A choreopolitical lens also contributes to research on the geographies of national identity. It traces how performances of nationality operate and the tensions they are underpinned by, whilst speaking to research that 
connects different spaces of, and approaches to, nationality, particularly in relation to affect. ${ }^{\text {lxxix }}$ The dancing Cambodian body cannot be contained by any singular approach to nationality, such as primordialist (the essentialist, unchanging reproduction of Cambodian nationality), social constructionist (the shifting configuration of that nationality vis-à-vis the reworking of dance), everyday (disabled lives and material objects) and affective (feelings of pride and hope). Rather, the power of nationality in Cambodian dance is probably due to its reproductive flexibility.

Choreopolitics also provides a way of thinking through how national affects emerge from individual bodies, slipping beyond choreographed moorings. In conceptualising national identity as a political feeling, researchers have examined how built landscapes, places and people shape national atmospheres, even if these are unpredictable. ${ }^{\operatorname{lxx}}$ However, affective nationalisms that depart from formal narratives are often seen to emerge from sites beyond state-sanctioned events. $^{\text {lxxi }}$ Although true here, such geographies are also more slippery. Choreopolitical experiments in the (re)production of nationality occur through disabled and non-disabled bodies that differently traverse government, teaching, and NGO settings, as well as rural and urban locations, and local (provincial), national and transnational spaces of activity. In the process, choreopolitics, and its affective possibilities, can open up varied political frames. This means that differentiated dancing bodies produce, perhaps inevitably, 'unsteady belongings s $^{\text {lxxii }}$ that coalesce into formations that include, but extend beyond, the nation.

\footnotetext{
'M.Franko, 'Dance and the Political: States of Exception', Dance Research Journal 38, 2006, pp. 318.

ii P.Merriman and R.Jones, 'Nations, Materialities and Affects', Progress in Human Geography, 41, 2016, pp.600-617.

iii M. Antonsich 'Nations and nationalism', in John A. Agnew, Virginie Mamadouh, Anna Secor, Jo Sharp, eds., The Wiley Blackwell Companion to Political Geography (Oxford, Wiley-Blackwell, 2015), pp. 297-310 (p.305). Regarding dance, see O.Kuhlke, 'Dancing in Foam City: Berlin and the Viscous Embodiment of German National Identity', in Olaf Kuhlke and Adam Pine, eds., Global Movements: Dance, place and bybridity (Maryland; London, Rowan and Littlefield, 2014), pp. 39-76.

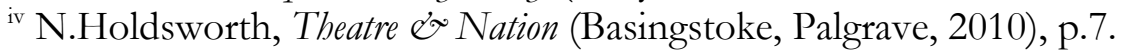


v The Preah Suramarit National Theatre in Phnom Penh was destroyed by fire in 1994 but never restored. It was later demolished for private redevelopment.

${ }^{v i}$ S.C.Shapiro, 'Dancing Off Centre', in S.Burridge and F.Frumberg, eds, Beyond the Apsara:

Celebrating dance in Cambodia (New Delhi, Routledge, 2010), pp. 109-120.

vii This observation is also made by Tuchman-Rosta in C. Tuchman-Rosta, Performance, Practice and

Possibility: How large-sclae processes affect the bodily economy of Cambodia's classical dancers (Ph.D.

Dissertation, UC Riverside, 2018) p.29.

viii R. Nelson, "Performance is Contemporary": Performance and its documentation in visual art in Cambodia', UD AYA Journal of Khmer Studies, 12, 2014, pp.95-143.

${ }^{\text {ix }}$ A. Lepecki, Exhausting Dance: Performance and the politics of movement, (New York and London;

Routledge, 2006), p. 87

x Ibid., p. 1

${ }^{x i}$ Ibid., p. 15

xii A. Lepecki, 'Choreopolice and Choreopolitics:, or , the task of the dancer', TDR, 57: 2013, pp.13-27; A.Lepecki, 'The Choreopolitical: Agency in the age of control', in Randy Martin, ed, The Routledge Companion to Art and Politics (Abingdon and New York, Routledge, 2015), pp.44-52; A.Lepecki, 'The politics of speculative imagination in contemporary choreography', in Rebekah J. Kowal, Gerald Siegmund, and Randy Martin, eds., The Oxford Handbook of Dance and Politics (Oxford, Oxford University Press, 2017), pp.149-168.

xiii E. Protopapa, 'Contemporary Choreographic Practice: From exhaustion to possibilising', Contemporary Theatre Review, 26, 2016, pp.168-182.

xiv Lepecki, 'Age of Control', p. 47

${ }^{x v}$ G.Deleuze, 'Postscript on the Societies of Control', October, 59, 1992, pp.3-7.

xvi Lepecki, 'Speculative Imagination' p. 155

xvii J. Rancière, Dissensus: On politics and aesthetics (London; New York, Bloomsbury, 2011), 'Thesis

7’, pp.44-45

xviii Rancière, 'Thesis 7', p. 44

xix Lepecki, 'Choreopolitce and Choreopolitics' p.23

${ }^{x x}$ D. P. McCormack, Refrains for Moving Bodies: Experience and experiment in affective spaces, (Durham; London, Duke University Press, 2013), p. 16

${ }^{x x i}$ Compare with N. Thrift, 'The still point: resistance, expressive embodiment and dance', in M.Keith and S. Pile, eds, Geographies of Resistance (London, Routledge, 1997), pp.124-151; N.

Thrift, 'Afterwords', Environment and Planning D: Society and space, 18, 2000, pp. 213-55

xxii See also P.Merriman, 'Architecture/dance: Choreographing and inhabiting spaces with Anna and Lawrence Halprin’, Cultural Geographies, 17, 2010, pp.427-449 (p.428).

xxiii A.Closs Stephens, 'The Affective Atmospheres of Nationalism', Cultural Geographies, 23, 2016, pp.181-198; A.Closs Stephens, 'Feeling "Brexit": Nationalism and the affective politics of movement', Geohumanities, 2019, pp.1-19 doi: 10.1080/2373566X.2019.1620623; Kulhlke 'Foam City'.

xxiv Merriman and Jones, 'Nations, Materialities, Affects'

${ }^{x x v}$ T.Mayer, 'Embodied Nationalisms', in Lynn A. Staeheli, Eleonore Kofman and Linda J.

Peake, eds., Mapping Women, Making Politics: Feminist perspectives on political geography (New York;

London, Routledge, 2004), pp.153-168.

xxvi D.Matless, Landscape and Englishness, (London, Reaktion, 1998).

xxvii S.Narbed, 'Creativity and the Dancing Body', in Harriet Hawkins, Creativity (New York;

London, Routledge, 2017), p.45.

xxviii T.Cresswell, "You Cannot Shake that Shimmie Here": Producing Mobility on the

Dancefloor', Cultural Geographies,13, 2006, pp. 55-77.

${ }^{x x i x}$ Y. Aoyama, 'The Role of Consumption and Globalization in a Cultural Industry: The case of flamenco’ Geoforum, 38, 2007, 103-113. 
${ }^{\mathrm{xxx}} \mathrm{K}$. Walsh, 'Irishness and Step Dancing in Newfoundland and Labrador', in Olaf Kuhlke and Adam Pine, eds., Global Movements: Dance, place and bybridity (Maryland; London, Rowan and Littlefield, 2014), pp. 23-38.

xxxi See the special issue of The Irish Review on 'Embodied Geographies of the Nation', 54, 2018, edited by N.Cronin and K.E.Till.

xxxii E.Militz and C.Schurr, 'Affective Nationalism: Banalities of belonging in Azerbaijan', Political Geography, 54, 2016, pp.54-63, (p.55).

xxxiii J. Shih Pearson, 'Unsteady Belongings: Rethinking the experience of nation through movement', Australasian Drama Studies 69, 2016, pp.111-141; Stephens 'Feeling "Brexit"”

xxiv S.A.Reed, Dance and the Nation: Performance, ritual and politics in Sri Lanka, (Madison Wisconsin, University of Wisconsin Press, 2010). P.8

${ }^{x x x v}$ F.Hughes-Freeland, Embodied Communities: Dance traditions and change in Java, (New York, Berghahn, 2008); C.Plancke, 'Contemporary Dynamics in Rwandan Dances: Identity, changing creativity and the globalisation of affect', Dance Research, 34, 2016, pp.150-169; Reed 'Dance and the Nation'; Tuchman-Rosta, 'Performance, practice, possibility.'

xxxvi Plancke, 'Contemporary Dynamics'

xxxvii Hughes-Freeland, 'Embodied Communities’ p. 20.

xxxviii Ibid., p. 28

xxxix A.Breed, Performing the Nation: Genocide, Justice, Reconciliation, (Calcutta, Seagull Books, 2014).

${ }^{x l}$ Plancke 'Contemporary Dynamics'; C.Plancke, 'Dance performances in post-genocide Rwanda: remaking identity, reconnecting past and present', Journal of Eastern African Studies, 11, 2017, pp.329-346.

xli Tuchman-Rosta, 'Performance, practice, possibility'. See also A.Rogers, 'Advancing the Geographies of the Performing Arts: Intercultural aesthetics, migratory mobility and geopolitics', Progress in Human Geography, 24, 2018, pp.549-568.

xlii T.S.Phim and A.Thompson, Dance in Cambodia (Oxford, Oxford University Press, 1999), p. 2

xliii 'HRH Princess Norodom Buppha Devi in conversation with Peter Sellars', Jerome Robbins

Division of the New York Public Library, $30^{\text {th }}$ April 2013, available at:

https://digitalcollections.nypl.org/items/70add590-343a-0131-c164-3c075448cc4b (last accessed

2nd August 2017); C.Tuchman-Rosta, 'From Ritual to Tourist Attraction: Negotiating the

transformation of classical Cambodian dance in a changing world', Asian Theatre Journal, 31,

2014, pp.524-41. (p.528).

xliv T.Shapiro-Phim 'Cambodia's “Seasons of Migration”", Dance Research Journal, 40, 2008, pp.56-

73 (p.63)

xlv T.Shapiro, Dance and the Spirit of Cambodia (Ithaca, Cornell University Press, 1994).

xlvi T.Shapiro-Phim, 'Mediating Cambodian History, the Sacred and the Earth', in Naomi Jackson and Toni Shapiro-Phim, eds., Dance, Human Rights and Social Justice: Dignity in Motion (Maryland, Scarecrow Press, 2008), pp. 304-322. (p.311).

xlvii But see S.Burridge and F.Frumberg, eds., Beyond the Apsara: Celebrating dance in Cambodia (Abingdon; New York, Routledge 2010) and Tuchman-Rosta 'Ritual to Tourist Attraction', 'Performance, practice, possibility'.

xlviii Ibid; Rogers, 'Advancing Geographies Performing Arts'.

xlix A.Cooper-Albright, 'Strategic abilities: negotiating the disabled body in dance', in A.Dills and A.Cooper-Albright, eds, Moving History/Dancing Cultures (Connecticut, Wesleyan University Press, 2001), pp.56-66 (p.58).

${ }^{1}$ See S.Burridge and S.V.Nielsen, eds., Dance, Access and Inclusion: Perspectives on Dance, Young People and Change (Abingdon and New York, Routledge, 2017).

${ }^{l i}$ Cooper-Albright, 'Strategic Abilities'; see also M.Ames 'Performing between Intention and Unconscious Daily Gesture. How Might Disabled Dancers Offer Us a New Aesthetic

Sensibility?' About Performance, 11, 2012, pp. 143-158. 
lii P.Kuppers, Disability and Contemporary Performance: Bodies on the edge, (Abingdon and New York, Routledge, 2003), p.2.

liii E.McGrath 'Dancing with Disability: An intersubjective approach', in D.Goodley, B.Hughes, and L.Davis, eds., Disability and Social Theory: New developments and directions, (Basingstoke, Palgrave Macmillan, 2012), pp.143-58; C.Veal 'Micro-bodily Mobilities: Choreographing a geographies and mobilities of dance and disability', Area, 50, 2018, pp.306-313.

liv A.Gartrell, 'A Frog in the Well: The exclusion of disabled people from work in Cambodia', Disability and Society, 25, 2010, pp.289-301; A.Gartrell, 'Problematizing Social Inclusion and Fostering Sense of Belonging for People with Disabilities in Rural Cambodia', in K.Soldatic, K.Johnson, eds, Disability and Rurality: Identity, gender and belonging (Abingdon and New York, Routledge, 2017), pp. 199-214. Social perceptions of disability in Cambodia are informed by Theravada Buddhism with disability often believed to be the karmic embodiment of a bad character from a previous life.

${ }^{\mathrm{lv}}$ K.A.Kauffman, Inclusive Creative Movement and Dance (Champaign IL, Human Kinetics, 2006). On inclusive arts more widely see A.Fox and H.Macpherson, Inclusive Arts Practice and Research: A critical manifesto (Abingdon; New York, Routledge, 2015).

lvi Lepecki, 'Speculative Imagination’ p. 155

lvii D.P. McCormack, 'Drawing out the lines of the event', Cultural Geographies 11, 2004, pp. 21120; G. Revill, 'Performing French folk music: dance, authenticity and non-representational theory', Cultural Geographies, 11, 2004, pp. 199-209.

lviii C.Veal, 'A Choreographic Notebook: Methodological Developments in Qualitative

Geographical Research', Cultural Geographies, 23, 2016, pp.221-245, (p.223)

lix T.Buckland, ed., Dance in the Field: Theory, methods and issues in dance ethnography (Basingstoke, Palgrave Macmillan, 1999); L.E.Dankworth and A.R.David, eds., Dance Ethnography and Global Perspectives: Identity, embodiment and culture, (Houndmills, Palgrave, 2014).

${ }^{1 x}$ C.Geertz, The Interpretation of Cultures (New York, Basic Books, 1977), p.3.

lxi D.Davida, Fields in Motion: Ethnography in the Worlds of Dance (Waterloo Canada, Wilfred Laurier University Press, 2011), p.10.

1xii A.Cooper Albright, Choreographing Difference: The body and identity in contemporary dance

(Middletown, Wesleyan University Press, 1997), p. 50.

lxii S.L.Foster, 'Introduction', in Susan Leigh Foster, ed., Corporealities (Abingdon; New York, Routledge, 1996) pp.xi-xvii (p.xi).

${ }^{1 x i v}$ Lepecki 'Choreopolicing and Choreopolitics', p. 20

lxv See https:// epicarts.org.uk/about/ (accessed 18 October 2019).

lxvi See Kauffman, 'Inclusive Creative Movement'; McGrath 'Dancing with Disability'.

lxvii Interview, Onn Sokny, then Epic Arts Senior Manager (now Co-Director), 19 ${ }^{\text {th }}$ May 2014

lxviii Interview, Laura Evans, then Epic Arts Co-Director, 19 ${ }^{\text {th }}$ May 2014

lxix Cooper-Albright, 'Strategic Abilities' p.61.

${ }^{1 x x}$ Respondent 33

lxxi Onn interview

lxxii Evans interview

lxxiii Interview Soy Chanborey, $15^{\text {th }}$ January 2018

lxxiv Ibid.

${ }^{1 x x v}$ Veal 'Micro-bodily Mobilities'.

lxxvi Epic Arts, Shake it Off parody. Available at: http:/ / epicarts.org.uk/shake-it-off/ (last accessed $2^{\text {nd }}$ Sept 2018).

lxxvii Ibid.

lxxviii See also Merriman, 'Architecture/dance'.

Ixxix Antonsich, 'Nations and Nationalism'; Closs Stephens, 'Affective Atmospheres', 'Feeling "Brexit" 
${ }^{1 x x x}$ S.Sumartojo, ' Dazzling Relief' floodlighting and national affective atmospheres on VE Day 1945', Jounral of Historical Geography, 45, 2014, pp.59-69.

${ }^{1 x x x i}$ For example, Closs Stephens, 'Affective Atmospheres'.

lxxxii Shih-Pearson, 'Unsteady Belongings'. 